\title{
Agente comunitário de saúde: perfil adequado a realidade do Programa Saúde da Família?
}

\author{
Community Health Agent: \\ status adapted with Family Health Program reality?
}

Karina Tonini dos Santos ${ }^{1}$

Nemre Adas Saliba ${ }^{1}$

Suzely A das Saliba M oimaz ${ }^{1}$

Renato M oreira Arcieri ${ }^{1}$

$M$ aria de Lourdes Carvalho ${ }^{1}$

${ }^{1}$ Odontologia Preventiva e

Social, Faculdade de

Odontologia, Universidade

Estadual Paulista. Ruaj osé

Bonifácio 1.193, Vila

M endonça. 16015-050

Araçatuba SP.

Abstract Thisstudy analysis the status and work reality of Community Health Agents, with the purpose of contributing to the improvement of the Brazilian Health System (SU S) in small cities. It was discussed aspects related to their participation in the team of the Family Health Program (PSF) and their interaction with the community. It was observed a lack of motivation and experience, which compromises the quality of Agents performance in the community. It is known that these findings are reflex and consequence of an established context. It is necessary the team rethink their practice, specially the managers, having always as fundament the principles that guide the SUS and PSF.

Key words Community health agents, $\mathrm{Health}$ services, Family Health Program
Resumo 0 presente artigo analisa o perfil e a realidade de trabalho dos agentes comunitários de saúde, visando contribuir para a otimização do Sistema Ú nico de Saúde (SUS), especialmente em municípios de pequeno porte. Foram discutidos aspectos relacionados a sua inserção na equipe do Programa deSaúde da Família (PSF) ea sua interação com a comunidade adscrita. O bservou-se, entre outros, que há falta de motivação e experiência por parte dos agentes, o que compromete a qualidadeda atuação na comunidade. Sabe-seque tais fatos encontrados são reflexos e consequências de todo um contexto estabel ecido. Torna-se necessário um profundo repensar de prática por parte da equipee, especialmente, dosgestores, tendo como base os princípi os que regem o SU S e o PSF.

Palavras-chave Agente comunitário de saúde, Serviços de saúde, Programa Saúde da Família 
Introdução

A estratégia da Saúde da Família foi apresentada como uma proposta de reorientação do modelo assistencial a partir da atenção básica, tendo como alicerce os princípios do Sistema Único de Saúde (SUS). Isso proporcionou uma postura dinâmica de atuação nas Unidades Básicas de Saúde (UBS), com definição deresponsabilidades entre os serviços de saúdee a população, rompendo o seu caráter passivo. Deste modo, os serviços passaram a buscar estratégias para desenvolver uma atenção integral à saúde de indivíduos e grupos, intervir sobre fatores de risco aos quais a população está exposta, promover parcerias por meio de ações intersetoriais e estimular o controle social.

Entretanto, cabe ressaltar que é de extrema importância o envolvimento governamental em áreas prioritárias como educação, saneamento, alimentação, renda, moradia e segurança, para a efetivação desse processo assistencial, possibilitando a adesão e mobilização das forças sociais e políticas em torno de suas diretrizes ${ }^{1}$.

O Programa de Saúde da Família (PSF) teve início com a criação do Programa de Agentes Comunitários de Saúde (PACS), pelo M inistério da Saúde, em 1991, e foi a partir daí que começou a seenfocar a família como unidade deação programática de saú de e não mais somente o indivíduo. A atenção passou a ser centrada na família, entendida e percebida a partir de seu ambiente físico e social, o que vem possibilitando às equipes que trabalham junto a estes sujeitos uma compreensão ampliada do processo saúde/doença e da necessidade de intervenções que transcendem as práticas curativas ${ }^{2}$.

O programa conta com uma equipe multiprofissional, composta por médico, enfermeira, auxiliar deenfermagem, agentes comunitários de saúdee, a partir de 2000, cirurgião-dentista, técnico em higiene dental eatendente de consultório dentário, proporcionando um grande avanço para a saúde da população, a qual cria vínculos de corresponsabilidade com os profissionais do setor, facilitando a identificação e o atendimento aos problemas de saúde da comunidade 3 .

Dentro da equipe, o agente comunitário de saúde (ACS) tem se revelado o ator mais intrigante e, muitas vezes, é considerado o protagonista no que se refere à relação de trocas de experiências estabel ecidas, especialmente entre os saberes populares de saúde e os conhecimentos médico-científicos 4 . O ACS, principal elo entrea ESF e a comunidade ${ }^{5}$, permite 0 fortalecimento do vínculo com a família, proporcionando a aproximação das ações de saúde ao contexto domiciliar, aumentando, com isso, a capacidade da população de enfrentar os problemas.

Tendo em vista a relevância do papel que os ACS assumem na equipe, constitui-seobjeto desse estudo conhecer o perfil ea realidade detrabaIho desses profissionais, no sentido de contribuir para a consolidação do SUS.

\section{M etodologia}

A pesquisa, caracterizada como um estudo exploratório descritivo, com abordagem quantiqualitativa, foi aprovada pelo Comitê de Ética em Pesquisa da Faculdade de Odontologia de Araçatuba - UNESP.

Os sujeitos da pesquisa foram esclarecidos quanto aos objetivos desta e àquel es que consentiram na participação tiveram suas identidades resguardadas em cumprimento aos preceitos éticos contidos na Resolução n 196/96 do CNS/ $\mathrm{MS}^{6}$. Para validar o instrumento utilizado e calibrar os pesquisadores, foi realizado um estudo piloto.

0 estudo foi realizado com a totalidade de agentes comunitários de saúde (ACS) $(n=38)$ que atuam em sete Equipes de Saúde da Família em quatro municípios de pequeno porte do Noroeste Paulista.

Inicialmente, foram realizadas visitas iniciais aos municípios e articulação com os profissionais da Secretaria M unicipal de Saúde e com os próprios agentes comunitários de saúde.

Os dados foram coletados por meio de entrevista, seguindo um roteiro semi-estruturado com perguntas abertas e fechadas, especialmente elaborado para pesquisa. 0 local das entrevistas com os profissionais foi um espaço reservado, no ambiente de trabalho deles, visando à privacidade, ética profissional e direito à cidadania de cada participante. As questões propostas abordaram características sociodemográficas e socioeconômicas, a forma de seleção dos agentes, atividades desenvolvidas por eles, grau de satisfação em atuar no PSF, frequência de visitas às famílias, relação interprofissional, pontos positivos e negativos do PSF, participação em capacitação introdutória e orientações em saú de bucal. Todos os participantes assinaram o termo de consentimento livree esclarecido.

Nas questões abertas, procurou-se recolher o maior número possível de percepções, captando a visão própria do indivíduo, sem induzir a resposta. Optou-se por anotar a fala dos profis- 
sionais durante a entrevista, visto que é importantequeo entrevistado sinta confiança eestabeleça uma relação de empatia com o entrevistador. Após anotado o que foi dito, perguntou-se ao entrevistado se o que estava escrito retratava o que ele realmente queria expressar.

A pesquisa qualitativa seguiu os princípios propostos por $\mathrm{M}$ inayo ${ }^{7}$, que visam 0 agrupamento de circunstâncias que dão sentido ao fato e não uma situação isolada, oferecendo liberdade para resgatar 0 importante na novidade dos temas, mesmo se a frequencia for pequena.

No processamento dos dados quantitativos e análise estatística, foi empregado o software de domínio público Epi Info 6.04.

\section{Resultados ediscussão}

\section{Universidade $x$ comunidade}

Percebe-se que se torna cada vez mais necessário e oportuno promover efortalecer os canais de integração e parceria entre as instituições de ensino superior e os municípios, no sentido de contribuir para a consolidação do SUS. Uma importantefunção da universidade éa deidentificar corretamente os problemas de saúdede cada município ou região e, de alguma forma, buscar solucioná-los, ou seja, o ensino e a pesquisa de vem ser direcionados para ações de impacto social que possibilitem melhores condições de vida para a população.

Os dados que serão apresentados nesse texto foram produzidos no interior do estudo "De senvolvimento de metodologia para a otimização do modelo deassistência à saúdeem municípios de pequeno porte no Estado de São Paulo", realizado por docentes, pós-graduandos e acadêmicos da Faculdade de O dontologia de Araçatuba, UNESP, cujo intuito foi obter um diagnóstico geral do sistema de saúde dos municípios citados acima, em busca dos nós críticos e, consequentemente, da melhoria das ações de saúde. Para tanto, foram realizadas entrevistas com elementos-chave (gestores, conselheiros municipais, profissionais da equipe de saúde, usuários, etc.), além deanálise dos Planos M unicipais deSaúdee da rotina das Unidades Básicas de Saúde.

Cabe ressaltar, ainda, que os dados de investigações devem ser publicados e estar disponíveis, bem como serem considerados na formulação de políticas públicas em saúde, considerações fortemente discutidas no 11 을 Congresso Mundial de Saúde Coletiva ${ }^{8}$.
Perfil dos ACS (dados sociodemográficos e socioeconômicos)

Desde o início da década de noventa, quando - Ministério da Saúde incorporou os agentes comunitários de saúde ao Sistema Ú nico deSaúde, ficou definido, pelo próprio ministério e pelas secretarias municipais de saúde, queestes trabalhadores, independentemente do nível de escolaridade, deveriam cumprir requisitos formais de residir há pelo menos dois anos na comunidade onde atuaria; ter idade mínima de dezoito anos; saber ler, escrever; ter disponibilidade de tempo integral para exercer suas atividades 9 .

A Portaria $n^{0} 648^{10}$ de 28 de março de 2006 traz a revisão de diretrizes enormas para a organização daAtenção Básica para o Programa Saúde da Família (PSF) e para o Programa dos Agentes Comunitários. Essa portaria deve ser respeitada para que o bom funcionamento dos programas se efetive eque eventuais falhas possam ser sanadas, imperando a interação entre os poderes que se colocam como responsáveis em organizar a saúde da população.

No presente estudo, a maioria dos profissionais é do gênero feminino; $34,2 \%$ apresentaram idade entre 18 e 29 anos, 39,5\%, entre 30 a 39 anos, $18,4 \%$, entre 40 a 49 anos e $7,9 \%$ com cinquenta anos ou mais.

Constatou-se que $5,3 \%$ dos agentes possuem o ensino fundamental incompleto; $65,8 \%, 0$ ensino médio completo; $7,9 \%$, ensino médio incompleto e $21,1 \%$, o ensino superior incompleto. A identificação de $65,8 \%$ dos agentes possuírem ensino médio é uma informação surpreendente eo que provavelmente define essa situação é a pequena oferta de empregos e os pequenos salários pagos na região. Os percentuais de escolaridade encontrados no presente estudo foram importantes para o processo de qualificação profissional que teveinício em agosto de 2006.

Apesar da grande importância que o ACS assume dentro da equipe, incluindo o aumento significativo de trabalho e responsabilidade, é discrepante a diferença salarial entre os membros da mesma. A renda média dos ACS foi de $R \$ 305,60$, enquanto os salários dos médicos variavam entre $R \$ 4.000,00$ a 8.000,00. Esse fator foi considerado um dos principais pontos negativos da profissão, portanto de insatisfação revelados por elas: "Acho que deveria ter um incentivo a mais no salário" ou ainda "O único proble ma éo salário baixo".

M esmo assim, observou-ser claramente a importância que os agentes atribuem ao trabalho 
que realizam: "Porquea genteéa primeira relação entre o paciente e o médico"; "Os problemas de minha área são resolvidos por mim (ACS) e pela enfermeira"; "Consigo tudo que precisa para a minha população adscrita". Por outro lado, o sentimento de desvalorização de sua profissão fica evidente em suas falas: "O salário épouco pelo o quea gente faz"; "N ão valorizam o trabalho da ACS"; "Falta de confiança nos agentes por parte dos gestores"; "Forma detratamento pessoal quemagoa".

\section{Realidade de trabalho dos ACS}

A maioria dos agentes $(65,8 \%)$ relatou que atua na área onde reside, fato essencial para que sejam estabelecidos o sentimento de confiança e cumplicidade entre eles e a comunidade. Outro ponto a se considerar, quanto à importância de se trabalhar onde reside, é o fato de compartiIhar os mesmos problemas, a mesma cultura, enfim, a mesma realidade. Deste modo, o papel de "tradutor" ${ }^{4}$ que os ACS assumem é muito mais verídico, pois eles participam do mesmo contexto físico esocial.

Dos agentes entrevistados, $47,4 \%$ estão a menos de um ano no PSF, caracterizando a alta rotatividade destes profissionais. Esse fato éconsiderado desfavorável para a comunidade, pois a questão do vínculo fica comprometida e os laços de confiança que deveriam ser estabelecidos acabam ficando estremecidos.

Alguns ACS parecem não compreender as funções que Ihes são atribuídas, até porque, muitas vezes, o que os leva a buscar o emprego são outros fatores como, por exemplo, a falta de trabalho e não propriamente a função que exercem. Citações como "Ter obrigação de realizar as visitas" e "M uitas famílias para poucas ACS" deixam claro essa percepção por parte dos mesmos.

A expansão da cobertura possibilitada pelo Programa de Saúde da Família vem garantindo a incorporação de um contingente expressivo de trabal hadores. Assim, verifica-se a ocorrência de diversas modalidades de contratação com vínculos que se distribuem desde os mais formais e protegidos pela legislação vigente, até os chamados contratos "informais".

Com o passar do tempo, a classe de ACS foi ganhando espaço no cenário do PSF e, com isso, foram se ampliando as suas aspirações de reconhecimento de sua identidade profissional e de seus direitos trabalhistas.

Entretanto, mesmo com a regulamentação da profissão ocorrida em 2002 (Lei no 10.501) ${ }^{11}$, verificou-se nesse estudo a existência de contra- tos de caráter precário, muitos sem garantias trabalhistas. Isso demonstra que os gestores municipais de saúde ainda não concebem o agente de saúde como sendo uma categoria permanente e essencial para o desenvolvimento do PSF.

Esse fato vem ao encontro de outros estudos, como os realizados em municípios do Rio Grande do Norte e da região metropolitana do Recife, ondeas formas de vinculação de trabalho realizadas entre as Secretarias de Saúde pesquisadas e os ACS são contratos temporários ${ }^{12,13}$. Sabe-se que, na maioria das vezes, estas formas de contratação contribuem marcantemente para a instabilidade dos ACS nos municípios, refletindo-se no conjunto de ações desenvolvidas por eles ${ }^{14}$.

As características da atuação dos agentes comunitários desaúdeexigem modalidades decontratação compatíveis com seus propósitos detrabalho, assegurando, acima de tudo, sua identificação e relacionamento com a comunidade ${ }^{15}$. A forma de vinculação do agente na secretaria de saúde influencia einterfere no processo detrabaIho, trazendo as seguintes consequências ${ }^{10}$ : descompromisso, desmotivação e insegurança, fazendo com que os agentes não se sintam comprometidos ao município e, por consequência, diminuam a produção no serviço.

Deacordo com o M inistério da Saúde², o ACS é responsável pelo acompanhamento de aproximadamente cento e cinquenta famílias que vivem em seu território de atuação, sendo imperativa sua total identificação com o mesmo. OsACS entrevistados revelaram quesão responsáveis, em média, por 97 famílias, e 78,9\% conhecem as famílias de sua área de abrangência. A maioria $(68,4 \%)$ realiza visitas semanais e os três temas mais abordados por eles durante as visitas domiciliares foram saúde geral, alimentação e assuntos familiares.

Por outro lado, percebeu-se que muitas ações realizadas pelos agentes são ainda muito centradas no enfoque curativo, com orientações e entrega de medicação, envio de exames, marcação de consultas: "porque antigamente não tinha essa facilidade de marcar consulta, pegar remédios".

Todavia, por meio desuas narrativas, foi constatado que alguns profissionais de saúde mostram-sesatisfeitos, ou melhor, realizados em prestar um serviço de caráter coletivo e o significado "cuidar" é muito forte entre eles. A questão do vínculo com o paciente, deum relacionamento de confiança mútua, fica evidente: "Porqueé um serviço onde todos se reúnem para atender a todos"; "Porque o paciente panha confiança na gente"; "Troca de afeto com pacientes, eles tem carinho e 
respeito pela $A C S$ "; "A auto estima fica elevada ao trabalhar com as pessoas"; "Q uando os problemas encaminhados são resolvidos, me sinto realizada"; "A maneira deconversar epoder ajudar aspessoasa melhorar hábitos de vida, como ACS posso ajudar as pessoas"; "Quando as pessoas te ouvem, vale a pena!"; "Recebo carinho, principalmente dos idosos e doentes"; "Ser útil ao ser humano".

Segundo Carvalho e Santos ${ }^{16}$, por mais bem estruturado que venha ser o Sistema Ú nico de Saúde, por mais abrangentee pormenorizada que venha a ser a legislação ordenadora do SUS, por mais recursos financeiros e materiais de que dispõe o sistema e por mais avançados que sejam os enunciados da política de saúde e os objetivos fixados na Lei Orgânica de Saúde, o SU S não funcionará a contento e os ideais nele traduzidos estarão fadados ao fracasso se não dispuser de recursos humanos qualificados e, obviamente, valorizados sempre.

Constatou-se que $52,6 \%$ dosACS não participaram de uma capacitação introdutória e que $89,5 \%$ não trabalhavam em serviços de saúde antes de entrar no PSF; mesmo assim, 78,9\% sentem-se seguros em atuar na função que exercem.

A saúde bucal é parte integrante e inseparável da saúde geral do indivíduo, estando diretamente relacionada com as condições de alimentação, moradia, trabalho, renda, meio-ambiente, transporte, lazer, liberdade, possedeterra, acesso aosserviços de saúde eà informação $0^{3}$. Para existir realmentea integralidade das ações, a saúde bucal deve ser considerada; entretanto, 60,5\% dos entrevistadosnão receberam informações sobre saúde bucal.

Levy et al. ${ }^{14}$ constataram em sua pesquisa que não houve uma capacitação para as ACS para o desenvolvimento de atividades visando promover a saúde bucal e as orientações restringem-se às gestantes e aos bebês, não havendo uma programação definida para a comunidade.

As práticas no PSF devem ser desenvolvidas por uma equipe interdisciplinar na medida em que participa e integra conhecimentos específicos de diversas áreas, com o objetivo comum de promover e manter a saúde da população.
Em um estudo realizado por Menegolla, PoIleto e Krahl' ${ }^{17}$, em 2003, as ACS relataram que a colaboração dos companheiros de equipe é imprescindível para o bom andamento das orientações e cuidados prestados à população, embora alguns observaram que é muito insipiente o envolvimento desta equipe em relação aos problemas da comunidade.

N esta pesquisa, também foi referida a falta de trabalho em equipe, sendo esta citada como causa de insatisfação: "Falta reunião para integração e conhecimento entre a equipe do PSF"; "A equipe precisa trabalhar junto"; "Falta ajuda dos médicos, enfermei ros e dentistas". Estefato corrobora, ainda, com o estudo de Pedrosa e Teles ${ }^{18}$, que verificaram dificuldades de integração de médicos e enfermeiros do PSF com agentes de saúde e ainda ressaltaram que, para os médicos, um dos problemas era a indefinição do papel do agentena relação médico/paciente/serviço, isto é, se deveria opinar/atuar diretamente nas intervenções diagnósticas eterapêuticas ou participar no levantamento de dados e facilitar o acesso ao serviço pela população.

\section{Considerações finais}

Assim, ainda que alguns pré-requisitos importantes para a atuação dos agentes no PSF se enquadrem dentro dos padrões exigidos, percebeuse que características como a falta de experiência, de integração com o restante da equipe e de motivação dos agentes comunitários pode comprometer a qualidade de suas ações na comunidade. Sabe-se que tais fatos encontrados são reflexos e consequências detodo um contexto estabelecido. Torna-se necessário um profundo repensar de prática por parte da equipe e, especialmente, dos gestores, tendo como base os princípios que regem o SUS e o PSF, para que o papel dosACS seja realmente entendido e, sobretudo, para que possam ser mais valorizados enquanto profissionais da área da saúde. Afinal, são eles que mantêm o contato estreito com os usuários dos sistemas. 


\section{Colaboradores}

NA Saliba, SAS M oimaz e RM Arcieri delinearam o estudo, orientaram a elaboração e aplicação dos questionários, bem como a análise dos dados e redação do artigo. ML Carvalho e KT Santos elaboraram e aplicaram os questionários, tabularam os dados e redigiram 0 artigo.

\section{Agradecimentos}

Aos agentes comunitários de saúde por permitirem que fossem realizadas as entrevistas. A Fapesp (Fundo de Amparo à Pesquisa do Estado de São Paulo) pelo suporte financeiro ao estudo.

\section{Referências}

1. Baldani M H, Fadel CB, Possamai T, Queiroz M GS. A inclusão da odontologia no Programa Saúde da Família no Estado do Paraná, Brasil. Cad Saude Publica 2005; 21(4):1026-1035.

2. Brasil. Ministério da Saúde. Cadernos de atenção básica - Programa da Saúde da Família. Brasília: M inistério da Saúde; 2000.

3. Brasil. Portaria no 1.444 de 28 de dezembro de 2000. Estabelece incentivo financeiro para a reorganização da atenção à saúde bucal prestada nos municípios por meio do Programa de Saúde da Família. Diário Oficial da União 2000; 28 dez.

4. Nunes M O, Trad LB, Almeida BA, Homem CR, M elo M CIC. $O$ agente comunitário de saúde: construção da identidade desse personagem híbrido e polifônico. Cad Saude Publica 2002; 18(6):1639-1646.

5. Oliveira EM, Spiri WC. Programa Saúde da Família: a experiência de equipe multiprofissional. Rev. Saude Publica 2006; 40(4):727-733.

6. Brasil. Conselho Nacional de Saúde. Resolução nº 196/96. Diretrizes e N ormas regulamentadoras de pesquisa envolvendo seres humanos. Brasília: Ministério da Saúde; 1996.

7. Minayo MCS. 0 desafio do conhecimento: pesquisa qualitativa em saúde. 8a ed. São Paulo: Hucitec; Rio de Janeiro: Abrasco; 2004.

8. Abrasco. Declaração do Rio [carta]. [site da Internet] [acessado 2007 abr 18]. Disponível em http://www.abrasco.org.br/noticias/noticia_ int.php?id_noticia $=47$

9. Brasil. Ministério da Saúde. Secretaria de Atenção à Saúde. Coordenação de Acompanhamento e Avaliação da Atenção Básica. Dez anos de saúde da família no Brasil. Brasília: Ministério da Saúde; 2004.

10. Brasil. Portaria no 648 de 28 de março de 2006. Dispõe sobre a revisão de diretrizes e normas para a organização da Atenção Básica para o Programa da Saúde da Família (PSF) e o Programa de Agentes Comunitários de Saúde (PACS). Diário Oficial da União 2006; 28 mar.
11. Brasil. Lei no 10.507 de 10 de julho de 2002. Cria a profissão e dá outras providências. Diário Oficial da União 2002; 10 jul.

12. Castro LJ, Vilar ALR, Fernandes PV. Precarização do trabalho do Agente Comunitário de Saúde: um desafio para a gestão do SUS. [site da Internet] 2004 [acessado 2006 set 25]. Disponível em: http://www. observatorio.nesc.ufrn.br/arquivos_enviados/Texto \%20ASC \%20pulicacao\%20ROREH S.pdf

13. Nascimento CM B. Precarização do trabalho do Agente Comunitário de Saúde: um estudo em municípios da região metropolitana do Recife [monografia de especialização]. Rio de Janeiro (RJ): Escola Nacional de Saúde Pública, Fundação Oswaldo Cruz; 2005.

14. Levy FM, M atos PES, Tomita NE. Programa de agentes comunitários de saúde: a percepção de usuários e trabalhadores de saúde. Cad Saude Publica 2004; 20(1):197-203.

15. Nogueira PR, Silva RBFZ. A vinculação institucional de um trabalhador suigeneris - 0 agente comunitário de saúde. [site da Internet] [acessado 2006 nov 03]. Disponível em: http://www.unb.br/ceam/nesp/ polrhs

16. Carvalho GI, Santos L. Sistema Ú nico de Saúde: comentários à lei orgânica da saúde (leis no 8080/90 e 8142/90). Campinas: Editora da Unicamp; 2002.

17. M enegolla VL, Polleto DS, Krahl M. O agente comunitário de saúde no desenvolvimento de seu trabalho. Rev Boletim da Saúde 2003; 17(2):81-93.

18. Pedrosa JIS, Teles JBM. Consenso e diferenças em equipes do Programa Saúde da Família. Rev. Saude Publica 2001; 35(3):303-311.

Artigo apresentado em 20/02/2008

Aprovado em 29/10/2008

Versão final apresentada em 01/12/2008 